\title{
Over 8000 pairs of specs for Africa
}

\author{
Charles Essex
}

*Global CARE, PO Box 61, Coventry CV5 6RQ, is a registered charity (No 326488). It is run by volunteers in England so the £8 a month it costs to sponsor a child goes to the child.

51 Dog Kennel Bank, Longley, Huddersfield HD5 8JB

Charles Essex, MB, acting senior clinical medical officer in community child health

BrMed J 1990;301:1435-6
"This boy is looking at both cameras at once." My wife's diagnosis seemed correct. From the photograph one of our sponsored Ugandan children did seem to have a squint. The director of the charity, who runs Global CARE` voluntarily from his home, told us that Ugandan children do not have eye tests and in a country of 17 million people Uganda has only five ophthalmologists.

We had supported the charity financially for several years and wanted to do something practical and thus a sight testing programme was conceived. The bones of the project were to test the sight of children, provide appropriate spectacles, and train a local health worker to carry on the work. The flesh of the project required as many spectacles as possible and finance for equipment and transport.

I booked three weeks annual leave nine months ahead in November, which was after the rainy season but before it was too hot so that we had a definite time limit in which to get the project organised. A feature in the local newspaper, which was syndicated to several other papers and on local radio, brought in thousands of pairs of secondhand glasses. Several opticians gave large numbers of glasses which had been handed to them when people changed their prescription and a paragraph in the charity's newsletter brought an excellent response. We collected over 8000 pairs.

My initial training goal had been to teach the designated health worker to test vision and to refract and to provide appropriate glasses from those available or a prescription if none were suitable. I also hoped to identify other treatable eye conditions so that these could be tackled on future visits. I estimated the cost of equipment at $£ 2000$, so every donor of spectacles received a thank you letter which included a mention of the cost and a polite request for a financial contribution. I also wrote to local benevolent organisations and the director of the charity wrote to trusts from which he had had help with previous projects. We were overwhelmed by the generosity of individuals, churches, and organisations.

The most useful advice came from a retired optician who had done similar work; this became the practical basis of the project. Firstly, the project was too ambitious - to teach sight testing and refraction in three weeks was unrealistic. I realised this when I tried to write an empirical guide to refraction which I would leave in Uganda. Sight testing and empirical provision of glasses would be the goal. Secondly, visual acuity of $6 / 12$, both eyes open, was to be the pass mark. Thirdly, those who did not achieve $6 / 12$ would be further tested by using a confirmation test (basically a twizzle stick with $a+0.5 \mathrm{D}$ lens on one side and a $-0.5 \mathrm{D}$ lens on the other) to see which gave an improvement in vision and then we continued to increase the strength of the appropriate lens. The optician also donated a focimeter to measure the strength of the glasses which were now occupying an increasing amount of space in our house. From then on many free lunch times and evenings were spent grading the glasses. This more

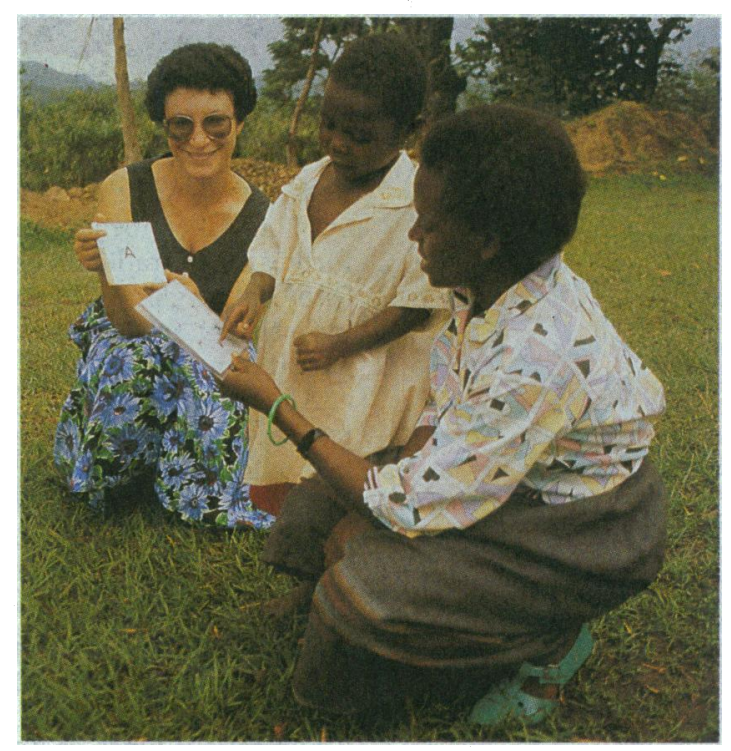

Often we would eat our lunch as we worked because there were so many people to test

realistic goal cost considerably less than the original estimate.

\section{Would the frames fit African noses?}

We were based in Mbale, the third largest town in Uganda, yet the downtown area was only the size of Holmfirth in West Yorkshire. The Ugandan charity workers were enthusiastic about our visit and had prepared a busy itinerary for us and advised the schools to expect us on certain days. We were apprehensive. Would the project be successful? Would the health worker learn quickly? Would the spectacles sent in advance arrive safely and those in our suitcases and hand luggage be allowed through the customs? Would spectacle frames for Caucasian faces fit African noses? Prayer is a powerful thing and everything went smoothly.

We took several thousand pairs of graded glasses (mainly those with spherical lenses or less than 1D of astigmatism) and a few pairs of industrial protective glasses and sunglasses. We had a wonderful welcome everywhere and the whole village would turn out to see the msungus (the white people; literally "those who run around in circles"). Steven, the man we were to train, was a bright medical entomologist, but as the government had no money to pay for mosquito eradication programmes he was now working full time for the charity. He learnt quickly.

My wife had spent a day with the orthoptists learning vision testing techniques and tips on how to detect those who were cheating so that we could both test vision from the day of our arrival in Uganda while I taught Steven. Contrary to my experience in the United Kingdom where children will cheat in order not to have to wear glasses the Ugandans actually wanted to 


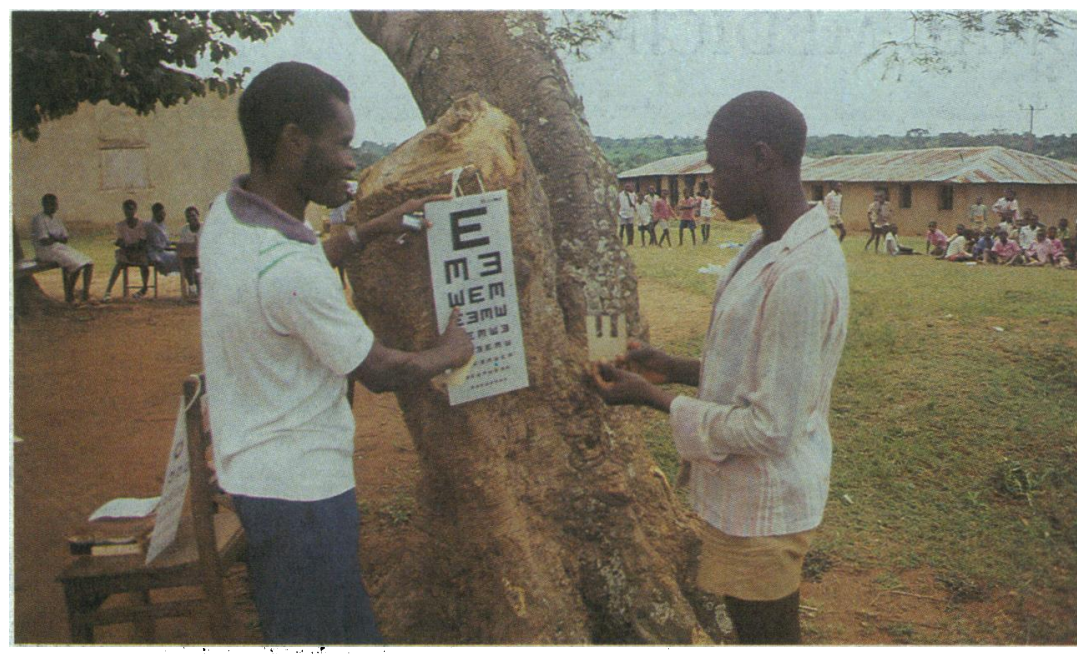

We tested vision outdoors with the charts hung on trees

wear them - was this a desire for Western technology or a mistaken belief that glasses would prevent a further deterioration in vision? We kept a pair of plain (protective) glasses to one side for those who had inconsistent results; using the placebo glasses often gave the answer.

After we had seen the children we tested their teachers. They earn 2000 Ugandan shillings a month but a loaf of bread is 300 shillings and a pair of spectacles (all of which are imported from Kenya) costs over 4000 shillings. We would then test other villagers if we had time. Most people spoke English and we used the Snellen chart, but the illiterate E chart was successful for those who did not. For older people with presbyopia the ability to thread a needle was a good test for the correct strength of bifocal correction. Often we would eat our lunch as we worked because there were so many people to test, leaving it as late as possible to pack our equipment and glasses into the car to go to the next village. We saw a surprisingly large number of corneal scars and eyes blinded by trauma and we gave the protective spectacles to trainees at the charity's industrial training workshop. Future appeals for secondhand glasses will specifically include protective glasses and goggles. We gave the dark glasses to three albinos we met, who must have suffered under the Ugandan sun.

Using this system of vision testing we were unable to correct gross astigmatism. Although I did some refraction, this was not satisfactory because I had to leave a modus operandi which Steven could reproduce. Those who had poor vision, which improved significantly with a pinhole, but not with spherical lenses (implying gross astigmatism), were given spectacle frames to offset the cost of spectacles. We were testing vision outdoors with the Snellen charts hung on treesclassrooms had no doors in the frames or glass in the windows let alone curtains, so achieving a dark room was impossible.

\section{People came $\mathbf{3 0 0}$ miles}

Word spread quickly and people would visit us in the evening at our hostel, sometimes bringing relatives from Kampala 300 miles away. Eventually we had to refuse to see people otherwise we would have been exhausted, and we directed them to return once Steven had set up a regular sight testing session at the charity's Mbale base.

Our attempts to collect statistics, which would have been the icing on the cake, of how many people were tested and how many had refractive errors were soon abandoned owing to the massive numbers screened. We gave away several hundred pairs of glasses and frames and, more importantly, trained Steven in sight testing and an empirical form of dispensing spectacles. We are still grading spectacles to maintain a regular supply of frames and graded spectacles with intermittent appeals when our stocks run low. Steven now holds weekly vision testing sessions at the charity's headquarters by appointment only; otherwise he would be overwhelmed.

We were formulating future projects for a second visit even before we left - for instance, to teach Steven to refract or to set up simple spectacle manufacture. The charity was keen to use my wife's skills as a dress designer and pattern cutter to improve the clothing workshop to produce and sell garments and generate income at a local level as well as to provide training and employment for local people.

We set up a sight testing programme and provided spectacles in an area where previously most of the population had no access to such a service and whose educational, social, and economic horizons would have been limited by poor vision. The cost has been a small financial outlay, three weeks of our annual leave (although considerably more time in preparation), several lectures on our return to our church and the local Rotary club, and articles for the local paper, charity newsletter, and the $B M \mathcal{F}$.

\section{Across a cultural divide}

It was a quarter to five when my pager went off. I groaned and uttered some expression of exasperation. The number on my pager was a urology ward; that could mean only one thing - a request for a medical opinion. Quarter to five on a Friday afternoon is not an hour at which I delight in looking for extra work and my thoughts had been turning to the usual Friday "research meeting." With little grace, I interrogated the resident who had telephoned me. It transpired that Dr Smith had been asked by her registrar to contact me. An elderly Indian man had been admitted to the ward earlier in the afternoon. He had flown from Delhi the previous night to join his daughter and had developed a urinary retention, requiring admission to hospital immediately on arrival. He had appeared breathless and a chest $x$ ray examination had been done. The astute resident quickly latched on to the abnormal film and wondered whether this man had active tuberculosis. Would I come and have a look?

He turned out to be a diminutive figure. He was a tiny man, cowed and bewildered in his bed. The hospital gown hung from his pathetic limbs in great baggy folds. A catheter bag hung rather disconsolately at his side. $\mathrm{He}$ wore a grubby scarf wrapped around his head like a makeshift bandage, a last vestige of his usual apparel. He shook hands tentatively, then greeted me in his own fashion, palms together, finger tips pointing to the ceiling. He spoke no English and with no interpreter available examination turned into a good natured pantomime. I mimicked sitting forward, he lay down.
I took huge breaths in and out, he looked quizzical. I chanted "ninety nine," he furrowed his brow and wished me "nighty night." Quite clearly he knew that he was dealing with an idiot but neither hostility nor dismay showed on his face. He.puffed and chanted and sat up and down to keep me happy. Later, as I approached his effusion with a needle, a broad grin appeared on his face and he gave a cheery "Just you carry on young man" wave.

I met his daughter later on. She told me that her father had never left the Punjab before. Her mother had died recently and she had flown out to bring the old man to Scotland. Within 48 hours he had been transported from his village home to the seething streets of Delhi, from Heathrow to the chill Glasgow rain. The laconic old man in front of me had obviously taken all this in his stride. A bizarre assault from a white coated Englishman was simply another experience in a busy couple of days.

When I left him he thanked me, smiling. He clasped his palms together and gently nodded his forehead over his pointing fingertips. It was a gracious, deferential gesture. I found his humility disconcerting. Why should a wise 84 year old man be so grateful that an alien culture should take an interest in his welfare? I remembered my feelings of exasperation when my pager had gone off. As I set off, half an hour late, to join my colleagues in the pub I felt rather humble. - ANDREW TREVETT, senior house officer, Glasgow 